\title{
CIRCULAÇÃO DE IDEIAS SOBRE A RENOVAÇÃO DO ENSINO SECUNDÁRIO NA REVISTA ESCOLA SECUNDÁRIA (1957-1961)
}

DOI: http://dx.doi.org/10.1590/2236-3459/61595

\author{
Fabiana Teixeira da Rosa \\ Universidade do Estado de Santa Catarina, Brasil. \\ Norberto Dallabrida \\ Universidade do Estado de Santa Catarina, Brasil.
}

\begin{abstract}
Resumo
Este trabalho tem por objetivo compreender a circulação de ideias sobre a renovação pedagógica do ensino secundário na revista Escola Secundária, publicada pela Cades, entre os anos de 1957 a 1961. Por um lado, busca-se analisar a circulação de ideias sobre a renovação do ensino secundário divulgadas por autores brasileiros, de outro procura-se compreender a difusão de experiências inovadoras do ensino secundário publicadas por autores estrangeiros. $O$ estudo fundamenta-se nos conceitos de produção, circulação e apropriação de bens culturais cunhados por Roger Chartier. O corpus documental é formado por 23 textos publicados na revista Escola Secundária que focalizam o ensino secundário num momento histórico de intensos debates educacionais.

Palavras-chave: circulação de ideias, renovação pedagógica, ensino secundário.
\end{abstract}

\section{CIRCULATION OF IDEAS ON THE RENEWAL OF SECONDARY EDUCATION IN THE MAGAZINE ESCOLA SECUNDÁRIA (1957-1961)}

\begin{abstract}
In this work we seek to understand the circulation of ideas on the pedagogical renewal of secondary education in the magazine Escola Secundária, published by Cades, between the years 1957 to 1961. On the hand, we analyze the circulation of ideas on the renewal of secondary education puth forth by Brazilian authors; or the other, we try to understand the dissemination of innovative secondary school experiences published by foreign authors. This study is based on the concepts of production, circulation and appropriation of cultural goods coined by Roger Chartier. The documentary corpus consists of 23 texts published in the magazine Escola Secundária focusing on secondary education at a historic moment of intense educational debates.

Key-words: circulation of ideias, pedagogical renewal, secondary education.
\end{abstract}




\title{
CIRCULACIÓN DE IDEAS SOBRE LA RENOVACIÓN DE LA ENSEÑANZA SECUNDARIA EN LA REVISTA ESCOLA SECUNDÁRIA (1957-1961)
}

\begin{abstract}
Resumen
Este trabajo tiene como objetivo comprender la circulación de ideas sobre la renovación pedagógica de la enseñanza secundaria en la revista Escola Secundária, publicado por la Cades, entre los años 1957 a 1961. Por un lado, se busca analizar la circulación de ideas en la renovación de la enseñanza secundaria publicado por autores brasileños, por el otro, busca entender la difusión de experiencias innovadoras de la escuela secundaria reportados por los autores extranjeros. El estudio se basa en los conceptos de producción, circulación y apropiación de bienes culturales acuñadas por Roger Chartier. El corpus documental consta de 23 artículos publicados en la revista Escola Secundária que se centran en la educación secundaria en un momento histórico de intensos debates educativos.

Palabras-clave: circulación de ideas, renovación pedagógica, enseñanza secundaria.

\section{CIRCULATION D'IDÉES SUR LA RENOVATION DE L'ENSEIGNEMENT SECONDAIRE DANS LA REVUE ESCOLA SECUNDÁRIA (1957-1961)}

\begin{abstract}
Résumé
Ce travail vise à comprendre la circulation des idées sur la renovation pédagogique de l'enseignement secondaire dans le magazine Escola Secundária, publié par la Cades, entre les années 1957 à 1961. D'une part, il cherche à analyser la circulation des idées sur le la rénovation de l'enseignement secondaire publié par des auteurs brésiliens; de l'autre, cherchent à comprendre la diffusion des expériences novatrices de l'enseignement secondaire rapportés par les auteurs étrangers. L'étude est basée sur les concepts de production, circulation et appropriation de biens culturels forgés par Roger Chartier. Le corpus documentaire se compose de 23 articles publiés dans le magazine Escola Secundária qui mettent l'accent sur l'enseignement secondaire dans un moment historique de intenses débats sur l'éducation.

Mots-clé: circulation d'idees, renovation pédagogique, enseignement secondaire.
\end{abstract}


stimulado pela atmosfera da redemocratização da sociedade brasileira, a partir da década de 1950, a estrutura rígida e tradicional do ensino secundário brasileiro - formatada pela Lei Orgânica do Ensino Secundário no apogeu da ditadura estadonovista - passou a ser flexibilizada e modernizada por iniciativas em diferentes instâncias educativas.

Sob a direção de Anísio Teixeira, desde 1952, o Instituto Nacional de Estudos Pedagógicos - Inep - instituiu várias campanhas para superar a fragilidade do sistema nacional de ensino, entre as quais a Campanha de Inquéritos e Levantamentos do Ensino Médio e Elementar - Cileme -, coordenada por Jayme Abreu, que resultou na publicação de artigos e um livro sobre a situação do ensino secundário brasileiro à luz de experiências internacionais.

Na gestão de Armando Hildebrand, a Diretoria do Ensino Secundário do MEC criou, por meio do decreto n. 34.638, de 17 de novembro de 1953, a Campanha Nacional de Difusão e Aperfeiçoamento do Ensino Secundário - Cades. O principal objetivo da Cades era promover cursos para professores leigos do ensino secundário, realizados durante 0 período de férias, com o intuito de prepará-los para o exame de suficiência, que conferia o registro de professor, viabilizando o ingresso na carreira do magistério secundário. A relevância desses cursos deve-se ao fato de que, na década de 1950, havia mais de $80 \%$ de professores leigos - geralmente profissionais liberais como advogados, médicos e engenheiros - que lecionavam em estabelecimentos de ensino secundário.

Para Pinto (2008, p. 165), as ações da Cades merecem destaque "pela ênfase que Ihes foi dada e/ou pelos resultados produzidos: 'as atividades relacionadas à orientação educacional (OE); a produção bibliográfica; e os cursos de orientação para exames de suficiência". Com relação à produção bibliográfica a elaboração e distribuição da revista Escola Secundária foi uma publicação de relevância por ser "uma das principais estratégias de divulgação dos preceitos e concepções profissionais compartilhados pelos técnicos da Cades" (Xavier, 2008, p. 153-154), sendo baseados nos possíveis ganhos com os conhecimentos da didática para a adaptação das práticas pedagógicas e na construção da identidade docente sintonizada com as ideias da Escola Nova.

Quando a Escola Secundária foi lançada, Gildásio Amado era o titular da Diretoria do Ensino Secundário, José Carlos de Melo e Souza coordenava a Cades e Luiz Alves de Mattos atuava como redator-chefe dessa revista. Com dezoito números publicados trimestralmente, durante cinco anos, e com uma média de vinte e um artigos por edição, o primeiro número de Escola Secundária foi publicado em junho de 1957 e o último, após mais de um ano da publicação do penúltimo número em 1961, que indicou o término da coleção. O último número da revista foi preparado em 1963, mas foi publicado posteriormente, sem indicação do ano (Apresentação, 196_, p. 6).

A revista Escola Secundária ocupava-se, com prioridade, de temas sobre a formação mais adequada do professor secundarista moderno e, para isso, tinha a organização das suas edições voltadas para a área da didática, conforme a descrição geral dos sumários: um espaço inicial, espécie de editorial, para a divulgação de textos escritos, geralmente, pelos integrantes da Cades; outra seção denominada Didática geral, que trazia textos mais técnicos e direcionados para todos os profissionais das escolas secundárias; a seção Orientação educacional com temas relacionados ao trabalho com adolescentes e seus familiares. Após esta seção há um grande bloco de subseções, 
sendo uma para cada disciplina ofertada pelo currículo do ensino secundário: Língua Vernácula, Latim, Línguas Estrangeiras, Matemática, Ciências Naturais, História do Brasil, Geografia, Trabalhos Manuais e Economia Doméstica, Desenho, Física, Química, Filosofia e Educação Física. Havia ainda a seção Educandários nacionais, na qual se divulgava novas experiências de instituições de ensino secundário, apresentada em apenas dois números da revista; e as seções Noticiário da Cades, com publicações acerca das suas ações e do MEC e das legislações para o ensino secundário, e Consultório didático, com textos enviados pelos professores ou leitores e concentrados na solução de seus problemas e suas dificuldades do trabalho cotidiano nas escolas.

Neste sentido, este trabalho tem como intuito compreender a circulação de ideias sobre a renovação pedagógica do ensino secundário brasileiro na revista Escola Secundária de 1957 a 1961. Esse período de análise se justifica pelo fato de Escola Secundária iniciar a sua publicação em meados de 1957 e a ano limite final deve-se ao fato do término da sua publicação regular, que não por acaso coincide com a promulgação da lei n. 4.024, de 20 de dezembro de 1961 - a primeira LDB.

Trata-se de uma conjuntura marcada pelos intensos debates em torno da Lei de Diretrizes e Bases da Educação Nacional, em boa medida desencadeados pelo substitutivo Lacerda (1958), que dividiu os educadores entre os defensores da escola pública e aqueles que representavam os interesses da escola privada, provocando a publicação do Manifesto dos Educadores Mais uma Vez Convocados (1959). O ensino secundário foi uma das questões que mais confrontava esses dois grupos porque a Igreja Católica ainda tinha uma ampla e consistente rede de escolas privadas nesse nível de escolarização e estava amparada pela Associação de Educação Católica - AEC. Desta forma, neste texto se analisa os artigos publicados na revista Escola Secundária que abordam as propostas de reestruturação do formato do ensino secundário, como a equiparação das modalidades do ensino técnico, o redesenho dos seus dois ciclos e a flexibilização curricular, preterindo os artigos que refletem sobre disciplina-saber específicas.

O trabalho se apoia no aporte teórico do historiador francês Roger Chartier (1988; 1992), que sugere o uso das categorias de produção, circulação e apropriação de bens culturais, fundamentado nos seus estudos sobre livros e leituras. Nesta direção, Magaldi e Xavier (2008) destacam as possibilidades de investigação sobre "a dimensão material das publicações pesquisadas, assim como para sua circulação e apropriação, aspecto que assinala a importante questão dos múltiplos destinos e usos observados em relação a uma mesma publicação" (p. 10).

A circulação de ideias movimenta e tece uma rede de relações e sentidos múltiplos que produz e legitima uma configuração no espaço social, envolvendo diversos atores sociais que produzem, se apropriam e fazem circular as ideias, concorrendo entre si e delimitando o espaço (Carvalho, 2009). A circulação de ideias, compreendida como um movimento de expansão multifacetado, é pensado no presente texto para analisar um periódico educacional. Assim, Catani (1996) chama a atenção para as possibilidades dos estudos que envolvem esses suportes materiais e a contribuição relevante para a produção e disseminação de conhecimentos educacionais, uma vez que são um locus privilegiado de divulgação teórica e de práticas educativas, bem como da circulação de ideias e modelos pedagógicos. Ela assevera que, 
de fato, as revistas especializadas em educação, no Brasil e em outros países, de modo geral, constituem uma instância privilegiada para a apreensão dos modos de funcionamento do campo educacional enquanto fazem circular informações sobre 0 trabalho pedagógico e 0 aperfeiçoamento das práticas docentes, o ensino específico das disciplinas, a organização dos sistemas, as reivindicações da categoria do magistério e outros temas que emergem do espaço profissional. Por outro lado, acompanhar o aparecimento e o ciclo de vida dessas revistas permite conhecer as lutas por legitimidade, que se travam no campo educacional. É possível analisar a participação dos agentes produtores do periódico na organização do sistema de ensino e na elaboração dos discursos que visam a instaurar as práticas exemplares. (Catani, 1996, p. 117)

As revistas especializadas em educação permitem, ao mesmo tempo, produzir e fazer circular ideias, tornando-as espaços de convergências e disputas de diferentes interesses, legitimando os saberes, as práticas e os atores educacionais, assim como circular e estruturar essas ideias em construção. Ao adotar as revistas educacionais como objeto de estudo da "circulação e estruturação do conhecimento educacional", Carvalho (2009, p. 190) esclarece que a abordagem deve-se conduzir por múltiplas facetas:

Como infraestrutura material da produção e da circulação do conhecimento, como espaço social e cultural da recepção e da difusão, da interpretação e da negociação desse conhecimento; e, consequentemente, como produto de uma rede comunicacional. [...] Ora, sendo as revistas palco, meio e produto da circulação e da estruturação do conhecimento educacional, elas são fonte privilegiada para a análise dos fenômenos da construção da internacionalidade educativa e da internacionalização da educação e das suas tensões. (Carvalho, 2009, p. 190)

A revista Escola Secundária tinha como alvo a divulgação de pesquisas educacionais para formar uma nova mentalidade docente, mais problematizadora e crítica em relação, principalmente, às legislações vigentes no período em estudo. O corpus empírico do presente trabalho é formado por artigos publicados na revista Escola Secundária que focalizam a renovação pedagógica do ensino secundário. A leitura do corpus é feita aqui considerando que todo "o documento é monumento" (Le Goff, 2003, p. 538), pois é necessário desestruturar o documento para evidenciar quais as circunstâncias de produção no espaço social e no tempo, procurando compreender os jogos de poder que envolvem as suas operações de produção, circulação e apropriação.

Nesta direção, o trabalho está estruturado em duas partes. Por um lado, analisa-se a circulação de ideias sobre a renovação pedagógica do ensino secundário brasileiro que foram divulgadas por autores ou instituições brasileiras, entre os anos de 1957 e 1961, em vários artigos publicados em Escola Secundária. De outra parte, procura-se compreender, por meio de quatro artigos, as experiências estrangeiras de ensino secundário publicadas nessa mesma revista.

\section{Os impasses do ensino secundário brasileiro}

A equipe de redação da revista Escola Secundária abriu a primeira edição com o artigo intitulado $A$ nossa revista, quando refletiu sobre "a espetacular expansão de nossa rede de estabelecimentos de ensino secundário e o seu crescimento em número de 
matrículas", nos últimos 25 anos. (A redação, 1957, p. 5). Toda essa ampliação, conforme o texto, foi em decorrência das ocupações profissionais que surgiram a partir da intensificação industrial e das novas necessidades e oportunidades que se criaram. Assim, os jovens buscavam o ensino secundário para se capacitarem e ascenderem socialmente, pois o enxergavam como a possibilidade de alcançarem melhores padrões de vida. O texto mostra também que foi grande o crescimento quantitativo do ensino secundário a partir da Lei Orgânica do Ensino Secundário (Souza, 2008), no entanto, faltou o mesmo desenvolvimento no viés qualitativo, "no sentido de evoluir de seu primitivo e rígido formalismo cultural para um sentido social mais amplo e realista, em que a inteligência e a cultura sejam postas a servir aos interesses mais vitais da coletividade" (A redação, 1957, p. 6). O ensino secundário, portanto, permaneceu absorvido por suas rotinas tradicionais e limitou-se a aceitar passivamente a massificação da educação secundária.

Na edição seguinte foi publicado na íntegra O substitutivo do Ministério da Educação e Cultura ao projeto de lei orgânica do ensino secundário (1957), que foi elaborado por uma comissão de técnicos do MEC. Nesse substitutivo precede um arrazoado apresentado pela referida comissão ao então ministro da Educação e Cultura Clóvis Salgado. Esse estudo apresentava sugestões de medidas práticas para conceder maior flexibilidade aos trabalhos escolares, de supressão dos programas oficiais e de ampliação da responsabilidade dos diretores e professores para determinarem as diretrizes das escolas, assuntos considerados novos à época e que provocavam "as mais desencontradas reações tanto de aplauso como de ceticismo e repulsa" (O substitutivo..., 1957, p. 3).

O artigo seguinte, intitulado As inspetorias seccionais do ensino secundário, publicado na terceira edição, trouxe o discurso proferido por Gildásio Amado (1957), no encerramento da VI reunião de inspetores seccionais do ensino secundário. $\mathrm{O}$ texto aborda a descentralização da inspeção federal do ensino secundário, iniciada em 1932 com a criação das inspetorias regionais, mas efetivada somente com a integração das inspetorias seccionais à Diretoria do Ensino Secundário no governo de Juscelino Kubitschek. Além disso, as inspetorias exerciam a função de "propagadoras das diretrizes gerais do ensino e receptoras e animadoras das necessidades e aspirações regionais" (Amado, 1957, p. 101).

No ano seguinte, no quarto número da revista, divulgou-se o Pronunciamento do Ministério da Educação e Cultura sobre o Projeto de Lei n. 2.222/57 que fixa as diretrizes e bases da educação nacional (1958). Esse texto foi resultado do estudo realizado por uma comissão convocada pelo ministro Clóvis Salgado acerca do projeto original das diretrizes e bases para a educação nacional - projeto de lei n. 2.222/57. Essa comissão era composta pelos professores Pedro Calmon, Lourenço Filho, Almeida Junior, Faria Goes e Anísio Teixeira, presidida pelo ministro em questão. Tantas foram as alterações que a comissão redigiu um documento novo e completo ao invés de oferecer apenas sugestões no próprio original.

Na edição seguinte foi publicado o texto Educação de grau médio (Oliveira Júnior, 1958), uma transcrição de um dos Doze ensaios sobre educação e tecnologia, publicados pela Cades em 1956 e de autoria do professor Ernesto L. de Oliveira Junior. O texto discute a evolução do número de matrículas nos diferentes ramos do ensino médio e 
superior, no Brasil. Os dados revelam, conforme Oliveira Junior (1958), que os jovens de nosso país buscavam o ensino secundário com o intuito de chegar as escolas superiores, no entanto, a maioria não conseguia ingressar, pois a escola secundária era "evidentemente divorciada da realidade brasileira" (p. 11). Desta forma, esse texto sublinha o descompasso entre o ensino secundário ainda tradicional e elitista e a sociedade brasileira em compasso de modernização.

O professor Valmir Chagas (1958), no texto intitulado Reformas, discute as legislações para o ensino no decorrer da história da educação brasileira, dando especial atenção ao projeto de lei de diretrizes e bases e as suas orientações para o ensino secundário, que tramitava à época no Congresso Nacional. No texto consta que o mérito desse projeto foi o de provocar um amplo debate acerca dos problemas da educação em nosso país, nos mais diversos espaços em que haviam pessoas interessadas e preocupadas com a "crise do ensino". Os problemas em evidência eram a "centralização e descentralização, exames de Estado, equivalência e uniformidade, colégio universitário e primeiro ciclo como curso de continuação, matérias obrigatórias e optativas, eliminação do Latim e predominância do Inglês sobre o Francês" (Chagas, 1958, p. 13).

A equipe de redação da revista Escola Secundária publicou, na sexta edição, o texto de abertura com o título Novos rumos para o ensino secundário (A Redação, 1958), no qual trata-se da temática urgente de novos rumos, novas perspectivas de expansão, progresso e aperfeiçoamento à educação secundária. O texto aborda essa etapa da escolarização como "saturada de rígido formalismo e embaraçada por um complexo ritualismo burocrático", não podendo mais continuar "nesse grau de esterilidade, inoperância e irresponsabilidade", herdado de um passado centralizador e ditatorial (A Redação, 1958, p. 3). Em busca da renovação pedagógica a Diretoria do Ensino Secundário atuava ativamente para atualizar e aperfeiçoar o ensino secundário brasileiro. Duas iniciativas da Diretoria do Ensino Secundário são destacadas no texto como importantes: a implantação definitiva da orientação educacional nas escolas secundárias brasileiras, prevista já na Lei Orgânica do Ensino Secundário (1942), e a divulgação das instruções de organização das classes secundárias experimentais as quais, conforme aponta o texto, possibilitariam a aplicação de novos métodos e processos de ensino:

Até a publicação destas instruções, o Brasil era talvez o único país do mundo em que a 'experimentação', no ensino de nível secundário, era absolutamente vedada por lei. Em todos os demais países, a experimentação, em maior ou menor escala, foi sempre considerada como de vital importância para a revisão e atualização dos currículos e métodos em voga, confiando-se à competência e ao senso de responsabilidade dos educadores a tarefa de explorar novas modalidades e melhores possibilidades de aprimorar 0 ensino secundário, tornando-o mais adaptado às realidades humanas e sociais, mais eficaz e rendoso para os alunos individualmente e para a sociedade. (A redação, 1958, p. 5)

O texto que seguiu nessa edição foi o da divulgação das Instruções sobre a natureza e a organização das classes experimentais (1958), propostas pelo titular da Diretoria do Ensino Secundário, Gildásio Amado, e homologadas pelo ministro da Educação, permitindo o seu funcionamento a partir do ano letivo de 1959. As classes secundárias experimentais tinham o objetivo de ensaiar métodos pedagógicos e processos escolares e apresentavam como normas gerais: a organização do currículo com vista à preparação 
geral e a sólida formação humana, atendendo as aptidões individuais; a articulação das várias disciplinas, a admissão de no máximo trinta alunos em cada classe; a redução do número de professores nas classes iniciais do ginásio para um convívio mais intenso com os alunos e evitar a transição brusca do primário para o secundário; reuniões periódicas dos professores para a discussão dos aspectos psicológicos das classes e orientação pedagógica; atividades adequadas às aptidões dos alunos; oportunidades aos alunos de permanecerem mais tempo na escola e oferta de atividades extracurriculares; estreitamento da relação entre professores e pais (Instruções..., 1958).

Norteadas pelos princípios escolanovistas as práticas escolares realizadas nas classes secundárias experimentais eram, de acordo com Vieira, Dallabrida e Steindel (2013, p. 6), "o que havia de mais avançado em termos de educação secundária à época”, uma vez que estavam baseadas em métodos ativos como, por exemplo, o de aprendizagem por projetos e o de estudos globalizados. Essas classes experimentais primavam, portanto, por práticas contrárias àquelas prescritas pela Lei Orgânica do Ensino Secundária (1942), em que predominava um viés tradicional. Caracterizadas "como de grande importância para a educação pública", as classes secundárias experimentais eram pautadas "em discussões de importantes intelectuais brasileiros que, a luz de discussões advindas do cenário internacional, propunham novas experiências para a educação brasileira" (Vieira; Dallabrida; Steindell, 2013, p. 7). Em particular, na elaboração das prescrições das classes secundárias experimentais, as classes nouvelles francesas, produzidas e animadas no Centre International d`Études Pedagogiques - Ciep -, tiveram importância decisiva.

No ano seguinte Escola Secundária iniciou a sua oitava edição, com o texto Melhor ambiência educativa para adolescentes (A Redação, 1959). O texto aborda a temática da escola e a necessidade de articulação com as outras instituições sociais para discutir e encontrar possíveis soluções para os complexos problemas da educação dos jovens brasileiros. Desta forma, refuta a ideia que a tarefa reservada a escola é a de conferir educação total da infância e da juventude. Também argumenta-se que a instrução pode depender da situação formal de aula, mas, a educação deve ser função de todas as instituições sociais em que os adolescentes estão vinculados.

Nesse sentido foi promovido, pela Diretoria do Ensino Secundário, em 1959, na cidade de Belo Horizonte, o I Encontro de Educadores que abrangeu o mesmo tema em discussão nesse texto, articulação das instituições sociais. As conclusões desse encontro foram publicadas pela revista Escola Secundária com o título Encontro de educadores (conclusões) (1959). Os participantes manifestaram, como meios essenciais à realização dos fins educativos, a instalação de um centro de orientação educacional em cada escola para conscientizar os alunos, os professores e os pais, da responsabilidade de cada um da escola em centro cultural para a comunidade onde está inserida; e a criação de classes experimentais. Na mesma edição Lauro de Oliveira Lima (1959) publicou o texto Sugestões aos pais - com relação à educação dos filhos nos colégios, no qual apresenta sugestões acerca das relações dos pais com o colégio, com os professores, com os alunos, com a sociedade e com os colegas de seus filhos.

Já na última edição do ano de 1959 foi publicada a palestra proferida pelo assistente de inspetorias, do Rio de Janeiro, Leonel Bogéa, intitulada $A$ escola secundária: sua organização administrativa e pedagógica (Bogéa, 1959). A palestra ocorreu na II Jornada 
de Estudos de Diretores de Estabelecimentos de Ensino Secundário, em outubro de 1958, e tinha por finalidade reunir as sugestões dos diretores que fossem possíveis de aplicação nos estabelecimentos e de ajustamento com a realidade da comunidade escolar, sugestões estas que necessitavam estar dentro das limitações legais para o ensino secundário.

$\mathrm{Na}$ edição seguinte, a primeira de 1960, o mesmo autor, Lauro de Oliveira Lima (1960), publicou o texto A reforma do ensino e a dúvida metódica, em que trabalha com a dificuldade de professores em aceitarem as mudanças na educação porque eles se acostumavam com o desenvolvimento das suas atividades em sala de aula e com o renome que muitos ganhavam diante dos alunos. Diante das reformas educacionais vários docentes ofereciam resistências para adotar novas técnicas e novos métodos de ensino. Ainda segundo o autor, a inclinação do professor era de se habituar à rotina e se acomodar com o trabalho que estava fazendo e que parecia estar dando certo, sem buscar novidades e sem se atualizar, no entanto, o mundo caminhava para a constante mudança.

Do mesmo modo o autor aborda a necessidade de repensar a escola secundária que asfixiava a criatividade do aluno. Utilizando como exemplo as discussões em torno das diretrizes e bases curriculares, ele indica que se deveria lançar mão do quantitativo em troca do qualitativo e do formativo, analisar a validade de cada disciplina que compõe o currículo e pensar "num ginásio onde se aprende a aprender, deixando os conteúdos com instituições especializadas" (Lima, 1960, p. 13). Seguindo essa perspectiva escolanovista, ele completa sua compreensão de escola secundária afirmando que

não se aprende uma língua estrangeira com duas aulas por semana durante 28 semanas anuais, como é a realidade brasileira. Por que, então, a hipocrisia de que o estudante secundário brasileiro estuda duas línguas estrangeiras? Por que não remeter o aluno a institutos especializados na aprendizagem das línguas, onde pode aprender em alguns meses de trabalho intensivo o que não aprende em sete anos de intermitências escolares? Por que não equipar cada grande cidade com alguns laboratórios científicos orientados por grandes mestres e para lá remeter os alunos que demonstraram aptidão para a pesquisa, ficando o ginásio como núcleo de orientação, de estudo dirigido, de controle da aprendizagem de vivências reais, remanso de meditação e formação da personalidade? O ginásio seria a biblioteca, o campo de esporte, o orientador educacional, a capela, a oficina de trabalhos manuais, a Arena de debates, de pesquisas, de estudo dirigido, o local em que as equipes, os clubes funcionariam sob a orientação de verdadeiros educadores? Por que empanturrar o ginásio com um horário que graficamente parece mais uma teia de aranha, onde o aluno se enreda como a mosca colhida pelas terríveis caçadoras? (Lima, 1960, p. 13)

Na mesma edição o professor Imideo Giuseppe Nérici (1960a) publicou o texto $A$ escola secundária e o adolescente. Inicia o texto analisando a composição da escola secundária brasileira em dois ciclos: o primeiro, chamado de ginasial, considerado rígido e com apenas um currículo; e o segundo, o colegial, dividido em cursos clássico e científico com o propósito de atender "uma necessidade de discriminação de aptidões dos educandos" (Nérici, 1960a, p. 14). Segundo o autor o colegial clássico era destinado aos adolescentes que apresentavam no ginásio alguma aptidão humanística e literária e 
deveria levá-los a cursar na universidade, de preferência, Direito, Belas Artes e Arquitetura. Já o colegial científico era aconselhado aos que revelavam disposição aos fatos naturais e científicos, levando-os a optarem, no ensino superior, pelos cursos de Engenharia, Medicina, Farmácia e Agronomia. No mesmo ano, mas em outra edição, esse autor publicou também A escola secundária brasileira (Nérici, 1960b), artigo que se propõe a debater a difícil tarefa dessa etapa escolar em atender às diversas necessidades culturais do nosso vasto país para melhor integrar cada indivíduo no seu meio social. Para o autor era possível resolver essa crucial tarefa por meio "dos currículos diferenciados, dos programas mínimos, das atividades extracurriculares e da mentalidade do professor" (Nérici, 1960b, p. 16).

Por fim, a equipe de redação da penúltima edição da revista Escola Secundária, apresentou o texto O movimento das novas classes experimentais (A Redação, 1961). O texto discutiu o interesse que as classes experimentais despertavam no país entre os intelectuais da educação, os professores, os pais e os alunos. O texto informa que existia, à época, uma decidida preferência das famílias pelos planos experimentais, comprovando a insatisfação diante dos currículos e métodos impostos pela Reforma Capanema e um crescente número de escolas que se preparavam para obter a autorização do MEC para funcionarem com classes experimentais, antes mesmo da validação das primeiras experiências autorizadas pelo Conselho Nacional de Educação, em 1959. De acordo com A Redação (1961),

dos 3.003 colégios secundários existentes no País, quase duas centenas preparam-se para esse cometimento, certos de que por meio das classes experimentais poderão obter melhor rendimento cultural e educativo de seus alunos, prestando melhor serviço à juventude e à coletividade brasileira. (p. 3)

Indicada como iniciativa ousada pelo titular da Diretoria do Ensino Secundário do MEC, Gildásio Amado, a experimentação de currículos, programas e métodos no ensino secundário brasileiro era vetada por lei até a aprovação do parecer n. 77 , de 1958, que legalizou a organização das classes experimentais. O Brasil era um dos poucos países que negava "aos educadores e professores o direito e a competência para organizarem e programarem seus próprios trabalhos, cerceando-lhes qualquer tentativa de experimentação pedagógica fora dos estreitos dispositivos legais", inclusive aos Colégios de Aplicação das Faculdades de Filosofia "que por sua natureza e finalidade deveriam ser eminentemente experimentais” (A redação, 1961, p. 4). Assim, a conclusão era a de que essa "alforria", que concede o direito e a capacidade dos educadores elaborarem seus planos escolares também implicava numa nova responsabilidade diante dos jovens e do próprio país.

Estes artigos publicados na revista Escola Secundária, de 1957 a 1961, abordam os principais impasses sobre o ensino secundário brasileiro. Em primeiro lugar constatam que, desde a Lei Orgânica do Ensino Secundário, o ensino secundário passou por um crescimento inédito, que não foi acompanhado pelo seu desenvolvimento qualitativo, em boa medida devido ao grande contingente de professores leigos. Apesar dessa expansão quantitativa o ensino secundário ainda era elitista porque a maioria dos adolescentes de jovens entre 11 e 18 anos estava excluída desse nível de escolarização. Em segundo lugar acreditam que o ensino secundário prescrito pela Lei Orgânica do Ensino 
Secundário tinha um formato tradicional, rígido e elitista, que estava em descompasso com a modernização da sociedade brasileira no período de redemocratização pós-Estado Novo. Nesta direção, vários autores constatam as dificuldades que os professores apresentavam em aceitar as mudanças propostas pelas leis, pois se acostumavam com as suas rotinas e ficavam alheios às mudanças que vinham transformando o ensino. Por fim, é possível verificar que a Diretoria do Ensino Secundário do MEC e a Cades foram consideradas como espaços institucionais que proporcionavam a renovação pedagógica, particularmente concretizada na autorização e organização das classes secundária experimentais, que representaram ousadia e internacionalização pedagógica.

\section{As classes nouvelles da França e a orientação educacional norte-americana}

A quinta edição da revista Escola Secundária, publicada em 1958, trouxe ao público o texto intitulado $O$ ensino secundário na França, de autoria do professor Jamil El-Jaick (1958). O autor analisa a organização, os princípios e o funcionamento do sistema de ensino secundário francês, comparando-o, oportunamente, com o ensino secundário brasileiro. Na França da década de 1950 El-Jaick diz que o ensino secundário era dividido em dois ciclos - o colégio e o liceu -, que correspondem, respectivamente, ao ginásio e ao colegial no Brasil. O primeiro ciclo oferecia a formação geral dos alunos de 11 a 15 anos e o segundo ciclo proporcionava a especialização científica ou literária dos alunos de 15 a 18 anos. O ensino secundário francês se destinava, à época, aos alunos de ambos os sexos e com idades entre 11 e 18 anos, não admitindo a matrícula para adultos, pois, teoricamente, não era um problema existente na França. Casos eventuais de adultos sem cursar ou concluir o ensino secundário eram solucionados pelo Centre National d'Enseignement par Correspondence et Radio. O certificado de conclusão do curso secundário - le baccalauréat - assegurava que o aluno tinha adquirido "cultura geral secundária" (El-Jaick, 1958, p. 5), bem como o habilitava para o ensino superior. Além da rede pública de ensino, na França o ensino secundário também era oferecido em colégios privados, sendo que a maioria vinculada à Igreja Católica.

El-Jaick (1958) ainda informou que os estabelecimentos do sistema secundário francês ofereciam atividades para os alunos, geralmente, pela manhã e pela tarde, de sorte que eles almoçavam gratuitamente no colégio. Algumas necessidades dos alunos ainda eram suplementadas pelo Estado, conforme os recursos disponíveis pelas famílias. As quintas-feiras não havia aulas e dava-se a oportunidade, neste dia, ao ensino religioso, de acordo com a tradição local. O ano letivo ocorria de outubro a meados de junho, sendo as férias maiores de junho a setembro. A carga horária era igual para todos os estabelecimentos, em torno de 23 a 25 horas semanais no primeiro ciclo e 26 a 33 horas semanais no segundo ciclo. No entanto, assinala que a exceção era representada pelas classes nouvelles, criadas em 1945 como resposta à crise provocada pela Segunda Guerra Mundial, sendo concebidas e instituídas pelo diretor de ensino secundário Gustave Monod, junto com um grupo de educadores e psicólogos. Elas tinham como principal objetivo a adaptação do "ensino de segundo grau à diversidade dos alunos e seus destinos", baseando-se em quatro princípios de funcionamento: "orientação positiva, uma equipe educativa, uma educação ativa e um ensino global" (Araújo; Dallabrida; Steindel, 2013, p. 9). 
Na mesma edição foi publicado o artigo sob o título O Centro Audiovisual de Saint Cloud - França, do professor Manoel Jairo Bezerra (1958), resultado do estágio que ele realizou nessa instituição pedagógica. O texto trata da criação e da finalidade do Centro, bem como de sua organização e atividades. O autor afirma que, em 1951, um decreto determinava que o ensino audiovisual na França deveria ser realizado por dois órgãos: pelo departamento de Ensino Audiovisual do Centro Nacional de Documentação Pedagógica e pelo Centro Audiovisual da Escola Normal Superior de Saint Cloud. Este último foi criado em 1947 para estudar sistemática e comparativamente os "acessórios de ensino" que seriam utilizados na educação francesa, buscando "a melhoria do rendimento didático dos meios audiovisuais e de estabelecer normas de emprego para esse material" (Bezerra, 1958, p. 31).

O texto $A$ equipe de orientação educacional no Ginásio Fordham de Nova lorque, de Theobaldo Frantz (1958), apresenta resultados obtidos no estágio de observação que o autor realizou durante um mês de 1957, tendo como foco o seu trabalho de orientação educacional. Com 772 alunos do sexo masculino o Ginásio Fordham era mantido pelos padres jesuítas, que tinham longa tradição pedagógica e, ao mesmo tempo, iniciativas inovadoras. A equipe de orientação educacional do colégio era formada pelo orientador educacional, por conselheiros de classe e pelos professores especialistas, prevendo-se, ainda, a contratação de orientadores assistentes.

O último texto desta parte reflete sobre O Centro Internacional de Estudos Pedagógicos de Sèvres, cujo autor é Manoel Jairo Bezerra (1959). Vinculado ao Ministério da Educação da França essa instituição pedagógica, criada em 1945, dedicavase a "formação pedagógica dos professores, já em exercício, e de todos aqueles que desejem escolher uma carreira ligada ao ensino" (Bezerra, 1959, p. 115), com a perspectiva de experimentar novos métodos de ensino para o momento da reconstrução da França. Inicialmente, segundo o autor, a criação do Centro contou com professores voluntários dispostos a participarem da experiência das classes nouvelles. Por solicitação do Ministério da Educação esses professores deveriam se reunir para discutirem os pontos fundamentais dessa experiência, surgindo, então, os estágios no Centre International d'Etudes Pédagogiques - Ciep -, sediado na cidade de Sèvres. Logo o Centro de Sèvres tornou-se o ponto de encontro de todos os profissionais da educação francesa e de estagiários de vários países para discutirem questões pedagógicas. Bezerra (1959) afirma também que o Centro de Sèvres era dirigido pela madame E. Hatinguais, também pioneira das classes nouvelles, e tinha como apoio o Lycée Pilote, em que os estagiários podiam "acompanhar e ter uma ideia prática e objetiva dos princípios da Escola Nova proclamados nas suas reuniões" (p. 115). O autor desse artigo diz que o Brasil havia organizado a participação dos professores de didática da Faculdade Nacional de Filosofia como estagiários no Centro de Sèvres, concluindo que

a equipe de professores do Colégio de Aplicação, chefiada pelo seu diretor, Professor Luiz Alves de Mattos, muito lucrou com esse intercâmbio cultural, tomando parte em várias conferências pedagógicas, assistindo a reuniões de 'conselho de classe', sessões de estudo dirigido, aulas e programas especiais de trabalho e de enriquecimento da experiência vital dos educandos do 'Lycée Pilote' de Sèvres; teve também oportunidade de 
assistir, ao vivo, ao funcionamento das 'classes nouvelles' e discutir com seus professores os pontos cruciais dessa nova orientação educativa. (Bezerra, 1959, p. 116)

Bezerra (1959) finaliza o texto dizendo que a Diretoria do Ensino Secundário, por meio da Cades, estava empenhada em oferecer aos professores de todo o nosso país uma formação pedagógica que fosse suficiente para elevar, cada vez mais, o nível de ensino. Poderia, igualmente, criar um centro pedagógico nacional utilizando, talvez no começo, a casa do professor e, posteriormente, com a aprovação da experiência, fundar centros pedagógicos regionais.

Nesta segunda parte do nosso trabalho, o foco de análise direcionou-se aos textos que apresentaram relatos de visitas ou estágios realizados por seus autores em estabelecimentos de ensino secundário no exterior. Há uma clara assimetria porque enquanto três artigos - um de Jamil El-Jaick e dois de Manoel Jairo Bezerra - focalizam o ensino secundário francês, especialmente aquele de caráter público e gratuito, somente o artigo assinado por Theobaldo Frantz analisa um colégio norte-americano e direção católico-jesuítica, explorando, especificamente, o serviço de orientação educacional. O olhar dos professores brasileiros sobre o ensino secundário francês confere ênfase à criação e implantação das classes nouvelles, que tinham sido observadas pelo professor Luís Contier, quando realizou estágio em Sèvres no início da década de 1950, bem como, posteriormente, por vários professores brasileiros. Essa visibilidade das classes nouvelles deve-se ao fato de elas terem se convertido no principal modelo pedagógico para as classes secundárias experimentais, que foram a principal experiência de renovação do ensino secundário brasileiro na década de 1950 e 1960.

\section{Considerações finais}

A criação da revista Escola Secundária e sua publicação regular entre 1957 e 1961 e a instituição das classes secundárias experimentais, em 1958, são as principais iniciativas que indicam o dinamismo dos primeiros anos da Diretoria do Ensino Secundário sob a direção do professor Gildásio Amado. É preciso lembrar que o ensino secundário era contemplado - mesmo de forma secundária em relação aos ensinos primário e normal - na Revista Brasileira de Estudos Pedagógicos e em Educação e Ciências Sociais - periódico educacional editado regularmente, a partir de 1956, pelo Centro Brasileiro de Pesquisas Educacionais - CBPE. No entanto, a revista Escola Secundária é singular porque era dedicada exclusivamente à escolarização média, isto é, ao antigo ensino secundário, bem como aos cursos técnico-profissionais que tiveram a equivalência efetiva na Lei de Diretrizes e Bases da Educação Nacional sob o conceito de ensino médio, assim como pelo fato de priorizar debates didático-pedagógicos voltados para as disciplinas-saber praticadas nas salas de aulas dos ginásios e colégios, tendo a indelével presença da Cades. A publicação regular de um periódico educacional voltado para o ensino secundário é fato inédito na história da educação brasileira, sendo parte integrante da visibilidade que esse nível de escolarização passou a ter no Brasil a partir dos anos 1950.

Em boa medida os textos publicados na revista Escola Secundária traduzem as questões que inquietavam a Diretoria do Ensino Secundário e, particularmente, a Cades. Assim, vários artigos expressam a preocupação com o crescimento expressivo do número 
de estabelecimentos de ensino secundário, tanto de ginásios, quanto de colégios, viabilizado pela Lei Orgânica do Ensino Secundário e solicitado pela sociedade brasileira em franco processo de industrialização e urbanização. Os debates em torno da reestruturação e modernização do ensino secundário provocados pela definição da Lei de Diretrizes e Bases da Educação Nacional também estiveram muito presente na revista da Diretoria do Ensino Secundário.

É importante salientar que o período da publicação regular desse periódico é o momento de maior embate entre defensores da escolar pública e da escola privada, desencadeado pelo substitutivo Lacerda. Desta forma, o formato tradicional, rígido, nacionalista e elitista do formato do ensino secundário vigente foi questionado em vários artigos, que indicavam a necessidade da sua renovação e democratização. Nesta direção, a experiência das classes secundárias experimentais foi oportunamente disseminada na revista Escola Secundária por meio da publicação das Instruções sobre a natureza e a organização das classes experimentais (1958), bem como por outros textos.

A revista Escola Secundária também representa um movimento inédito de circulação internacional de professores secundaristas em países ocidentais. Dos quatro artigos publicados sobre o ensino secundário no exterior três focalizam a França e apenas um os EUA, indicando que, nesse nível de escolarização, a perspectiva francesa ainda era dominante. $O$ fato que tem maior relevo e novidade é, efetivamente, o modelo pedagógico das classes nouvelles, criado no imediato pós-Segunda Guerra, aprimorado e divulgado no Centre International d`Études Pedagogiques - Ciep -, local de visitas e estágios de vários professores brasileiros desde o início da década de 1950.

Esse modelo pedagógico foi a principal referência para os ensaios inovadores do professor Luís Contier no colégio paulista onde lecionava e, sobretudo, para a experiência das classes secundárias experimentais. Os modelos pedagógicos de renovação do ensino secundário, como o Plano de Unidades Didáticas de Morrison, usado no inovador Colégio Nova Friburgo, não foram contemplados na revista da Diretoria do Ensino Secundário, que publicou somente um texto sobre a orientação educacional em um educandário norte-americano dirigido pelos jesuítas. Ademais, a revista Escola Secundária não publicou artigo de autores estrangeiros como fez, por exemplo, o periódico Educação e Ciências Sociais, mas fez circular textos de professores brasileiros sobre o ensino secundário nos EUA e, principalmente, na França.

\section{Referências}

A REDAÇÃO. A nossa revista. Escola Secundária. Rio de Janeiro: MEC, n. 1, 1957, p. 59.

A REDAÇÃO. Novos rumos para o ensino secundário. Escola Secundária. Rio de Janeiro: MEC, n. 6, 1958, p. 3-5.

A REDAÇÃO. Melhor ambiência educativa para adolescentes. Escola Secundária. Rio de Janeiro: MEC, n. 8, 1959, p. 3-4.

A REDAÇÃO. O movimento das novas classes experimentais. Escola Secundária. Rio de Janeiro: MEC, n. 17, 1961, p. 3-4.

AMADO, Gildásio. As inspetorias seccionais do ensino secundário. Escola Secundária. Rio de Janeiro, MEC, n. 3, 1957c, p. 101-102. 
APRESENTAÇÃO. Escola Secundária. Rio de Janeiro, MEC, n. 18, 196_, p. 5.

ARAUJO, Elisabete Maria de; DALLABRIDA, Norberto; STEINDEL, Gisela Eggert. Gustave Monod e as classes nouvelles: apropriações e renovações no ensino secundário francês. In: COLÓQUIO ENSINO MÉDIO, HISTÓRIA E CIDADANIA, 8, 2013. Anais ... Florianópolis: Udesc, 2013. p. 1-12. Disponível em <http://www.revistas.udesc.br/index.php/EnsinoMedio/article/view/4331/3035>. Acesso em 30 nov. 2015.

BEZERRA, Manoel Jairo. O Centro Audiovisual de Saint Cloud - França. Escola Secundária. Rio de Janeiro, MEC, n. 5, 1958, p. 30-34.

BEZERRA, Manoel Jairo. O Centro Internacional de Estudos Pedagógicos de Sèvres. Escola Secundária. Rio de Janeiro, MEC, n. 8, 1959, p. 115-116.

BOGÉA, Leonel. A escola secundária: sua organização administrativa e pedagógica. Escola Secundária. Rio de Janeiro, MEC, n. 11, 1959, p. 4-13.

BRASIL. Lei n. 9.394, de 20 de dezembro de 1996. Diário Oficial da União. Rio de Janeiro, 23 dez. 1996. p. 27833. Disponível em <http://www2.camara.leg.br/legin/fed/lei/1996/lei-9394-20-dezembro-1996-362578publicacaooriginal-1-pl.html> Acesso em 5 set. 2013.

CARVALHO, Luís Miguel. Notas para um estudo da circulação e estruturação do conhecimento educacional na imprensa de educação e ensino. In: Ó, Jorge Ramos do; CARVALHO, Luís Miguel. Emergência e circulação do conhecimento psicopedagógico moderno (1880-1960): estudos comparados Portugal-Brasil. Lisboa: Educa, 2009, p. 173194.

CATANI, Denice Barbara. A imprensa periódica educacional: as revistas de ensino e o estudo do campo educacional. Educação e Filosofia. Uberlândia, v. 10, n. 20, 1996, p. 115-130.

CHAGAS, Valmir. Reformas. Escola Secundária. Rio de Janeiro, MEC, n. 5, 1958, p. 1318.

CHARTIER, Roger. A história cultural entre práticas e representações. Lisboa: Difel, 1988.

CHARTIER, Roger. Textos, impressão, leituras. In: HUNT, Lynn. A nova história cultural. São Paulo: Martins Fontes, 1992, p. 211-238.

EL-JAICK, Jamil. O ensino secundário na França. Escola Secundária. Rio de Janeiro, MEC, n. 5, 1958, p. 4-10.

ENCONTRO DE EDUCADORES (CONCLUSÕES). Escola Secundária. Rio de Janeiro, MEC, n. 8, 1959, p. 5-6.

FRANTZ, Theobaldo. A equipe de orientação educacional no ginásio Fordham de Nova lorque. Escola Secundária. Rio de Janeiro, MEC, n. 7, 1958, p. 32-35.

INSTRUÇÕES SOBRE A NATUREZA E A ORGANIZAÇÃO DAS CLASSES EXPERIMENTAIS. Escola Secundária. Rio de Janeiro, MEC, n. 6, 1958, p. 8-12.

LE GOFF, Jacques. História e memória. Campinas: Unicamp, 2003.

LIMA, Lauro de Oliveira. Sugestões aos pais - Com relação à educação dos filhos nos colégios. Escola Secundária. Rio de Janeiro, MEC, n. 8, 1959, p. 7-10.

LIMA, Lauro de Oliveira. A reforma do ensino e a dúvida metódica. Escola Secundária.

Rio de Janeiro, MEC, n. 12, 1960, p. 10-13. 
MAGALDI, Ana Maria Bandeira de Mello; XAVIER, Libânia Nacif. Impressos e história da educação: usos e destinos. Rio de Janeiro: 7Letras, 2008.

NÉRICI, Imideo Giuseppe. A escola secundária e o adolescente. Escola Secundária. Rio de Janeiro, MEC, n. 12, 1960a, p. 14-19.

NÉRICI, Imideo Giuseppe. A escola secundária brasileira. Escola Secundária. Rio de Janeiro, MEC, n. 14,1960b, p. 12-17.

O SUBSTITUTIVO do Ministério da Educação e Cultura ao projeto de lei orgânica do ensino secundário. Escola Secundária. Rio de Janeiro, MEC, n. 2, 1957, p. 3-25.

OLIVEIRA JUNIOR, Ernesto L. de. Educação de grau médio. Escola Secundária. Rio de Janeiro, MEC, n. 5, 1958, p. 10-12.

PINTO, Diana Couto. Campanha de Aperfeiçoamento e Difusão do Ensino Secundário: uma trajetória bem-sucedida? In: MENDONÇA, Ana Waleska; XAVIER, Libânia Nacif. Por uma política de formação do magistério nacional: o Inep/MEC dos anos 1950/1960. Brasília: Inep, 2008, p. 145-177.

PRONUNCIAMENTO do Ministério da Educação e Cultura sobre o projeto de lei $\mathrm{n}$. 2.222/57 que fixa as diretrizes e bases da educação nacional. Escola Secundária. Rio de Janeiro, MEC, n. 4, 1958, p. 3-23.

SOUZA, Rosa Fátima de. História da organização do trabalho escolar e do currículo no século XX: ensino primário e secundário no Brasil. São Paulo: Cortez, 2008.

VIEIRA, Letícia; DALLABRIDA, Norberto; STEINDEL, Gisela Eggert. Uma análise acerca das classes experimentais do ensino secundário paulista (1955-1964). COLÓQUIO ENSINO MÉDIO, HISTÓRIA E CIDADANIA, 8, 2013. Anais... Florianópolis: Udesc, 2013, p. 1-12. Disponível em <http://www.revistas.udesc.br/index.php/EnsinoMedio/article/view/ 4331/3035>. Acesso em 30 mar. 2014.

XAVIER, Libânia Nacif. Modos de fabricação da identidade docente na revista Escola Secundária (Cades/MEC: 1957-1963). In: MAGALDI, Ana Maria Bandeira de Mello; XAVIER, Libânia Nacif. Impressos e história da educação: usos e destinos. Rio de Janeiro: 7Letras, 2008, p. 152-166.

FABIANA TEIXEIRA DA ROSA, mestre em Educação pela Universidade do Estado de Santa Catarina, é técnica em assuntos universitários do Centro de Ciências da Administração da mesma universidade.

Endereço: Avenida Madre Benvenuta, 2037 - 88035-001 - Florianópolis - SCBrasil.

E-mail: fabirosa11@hotmail.com.

NORBERTO DALLABRIDA, doutor em História Social pela Universidade de São Paulo, é professor no Programa de Pós-Graduação em Educação da Universidade do Estado de Santa Catarina.

Endereço: Rua Henrique Bruggemann, 40/304 - 88015-650 - Florianópolis - SC Brasil.

E-mail: norbertodallabrida@gmail.com.

Recebido em 13 de janeiro de 2016.

Aceito em 19 de julho de 2016. 